\title{
Personal News
}

\section{Hans Frohberg 1901-1970}

\section{Nachruf}

Hans Frohberg starb am 30. August 1970 nach schwerer Krebserkrankung in seiner Wahlheimat Canada in Toronto. Mit ihm verliert die Lagerstättenkunde einen hervorragenden Vertreter aus der Freiberger Schule von Schumacher und Kolbeck. Etwa 1920 kam dort durch einen glücklichen Zufall eine Zahl hochinteressierter Studenten der Montangeologie zusammen, die sich später als Gelehrte oder Experten auf verschiedenen Gebieten ihres Faches in aller Welt auszeichneten. Ich nenne Buchmann, Donatr, Frohberg, Oelsner, ReH - der letzte jetzt der einzige Überlebende dieser hochintelligenten, fleißigen und vitalen Gruppe. Völlig verschieden im Temperament, aber gleich im Streben. Mit fast allen war der Unterzeichtsete freundschaftlich verbunden, von allen hat er wissenschaftliche und menschliche Anregung und Hilfe genossen, wohl am reichsten durch seinen lieben Haxs Frohberg. Mit großer Freude und jetzt Wehmut erinnere ich mich der Besuche in seinem Heim in Toronto, erstmalig nach dem internationalen Kongreß in Mexiko; wo er uns, d.h. Doris Schachner, Arne LaItaxari und mich, ohne Rücksicht auf seine anderen Beanspruchungen und Aufgaben in sechstägiget Exkursion durch die wichtigsten Erzdistrikte Ontarios in den prächtigen Oktobertagen 1956 führte.

FrohberG, an sich in Österreich geboren, verlebte seine ganze Jugend in Dresden, dann das Studium an der traditionsgeladenen Bergakademie in Freiberg, wo er mit dem Bergingenieurdiplom zunächst sein Studium abschloß. Es zog den jungen Bergingenieur zuerst nach Amerika, wo er unter den Lagerstättenkundlern W. Emmons und J. W. Gruner in Minneapolis sich weiterbildete, bald aber im canadischen Goldgrubendistrikt die Leitung einer Grube übernahm. Diese Tätigkeit gab ihm den Start zu einer großen Erfahrung in Goldlagerstätten und zu seiner späteren Tätigkeit als der angesehenste Gutachter in Goldgangvorkommen. Die wirtschaftliche Flaute der beginnenden $30 \mathrm{er}$ Jahre nutzte er aus, bei seiner alten Alma mater unter der Leitung von F. Schumacher über Probleme seines Arbeitsgebietes zu promovieren. 1932 war er wieder in Minneapolis, wo er unter Mithilfe seines um 6 Jahre älteren Freundes Gruner von neuem seine Bergingenieurtätigkeit, meist wieder ,im Gold“, aufnahm.

Er lernte eine Unzahl von Gruben kennen und erwarb sich die Freundschaft der angesehensten Persönlichkeiten des canadischen Bergbaus, aber auch der Wissenschaftler der Universitäten wie des canad. Geol. Survey. Durch viele Veröffentlichungen, mehr noch durch seine sehr zahlreichen klaren, wohlüberlegten und, wo nötig, scharf kritischen Gutachten, die leider der Allgemeinheit meist nicht zugänglich sind, gewann er großes Ansehen, das ihm viele Ehrungen einbrachte, z. B. war er zeitweise Präsident der Canad. Mineralogical Association und Vorsitzender oder Officer anderer Gesellschaften. Besonders freute er sich mit Recht daruiber, daß man ihm die amtliche Stellung des Technical Consultant des Toronto Stock Exchange antrug, in welcher Eigenschaft er pflichtmäßig über die Zulassung der Grubenanteile bei der canadischen Börse gutachtlich tätig sein mußte, ein Amt also, das - in allen Ländern mit schnell wachsendem Bergbau entstehen ja immer viele unseriöse Unternehmungen - größte Sachkenntnis ebenso verlangt wie Kritik und zuverlässigste Unbestechlichkeit. Weltwirtschaftlich bedeutsam war die Entwicklung einer der größten Fluoritlagerstätten der Erde in Mexiko, (im Staat San Luis Potosi). Der Unterzeichnete ist Frohberg besonders verpflichtet durch seine Hilfe bei der englischen Ausgabe des Erzmikroskopiebuches, bei dem er mit seiner lieben Frau Hertha wesentliche Teile hervorragend und sachkundig übersetzte. Wissenschaftlich war er außer wirtschaftlichen Problemen des Bergbaus und der Lagerstättengeologie besonders der speziellen Mineralogie zugetan in Erinnerung an seinen alten Lehrer in Freiberg, F. KolвECK. Er war ein hervorragender Mineralkenner und ein Sammler exquisiter Stücke. Ein Mineral, $\mathrm{FeTe}_{2}$, zunächst nur in winzigen Mengen erkannt in einem canadischen Vorkommen (Robb Montbray Mine), ist nach ihm Frobbergit genannt worden. Inzwischen ist es in größerer Menge in einigen der Au-Te-Vorkommen im westlichen Rumänien beobachtet worden, außerdem soll es in Kalgoorlie (W. Australien) vorkommen.

Wir werden HaNS Frohberg in lieber Etinnerung behalten!

Paul Ramdohr (Heidelberg)

Responsible for text Prof:. Dr.-Ing. A. Matcher, D-8000 München 2, Institut für allgemeine und angewandte Geologie und Mineralogie der Universität.

Responsible for advertiscments: Edgar Seidler, D-1000 Berlin 15, Kurfürstendamm 237. Springer-Verlag, Berlin, Heidelberg, New York. Copyright (C) by Springer-Vetlag Berlin Heidelberg 1972. Druckerei Hans Meister KG, Kassel 